\title{
Superplastic Forming of a Three-Stage Hemispherical 5083 Aluminium Profile
}

\author{
Muthusamy Balasubramanian ${ }^{1}$ - Pasupathy Ganesh ${ }^{2}$ - \\ Kalimuthu Ramanathan ${ }^{3}$ - Velukkudi Santhanam Senthil Kumar2,* \\ ${ }^{1}$ Anna University, University College of Engineering-Ramanathapuram, India \\ 2Anna University, College of Engineering-Guindy, India \\ ${ }^{3}$ Alagappa Chettiar College of Engineering and Technology-Karaikudi, India
}

Three-stage superplastic blow forming characteristics of 5083 aluminium sheets in a hemispherical die cavity have been studied as a function of forming pressure, die entry radius, coefficient of friction, forming time and forming height, both experimentally and using finite element method in this work. Optimum forming pressure for achieving uniform thickness in a complex three-stage radius dome profile has been established. Variations in thickness profile are observed experimentally and in FEM analysis in three different die entry regions. The thickness profile has also been predicted as a function of the friction coefficient and die entry radius. The changes in pole thickness, relative height and relative radius of the profile along with the thinning factor are discussed.

Keywords: superplastic forming, three-stage radius hemispherical shape, experimental, FEM, $5083 \mathrm{Al}$ alloy

Highlights

- $\quad$ Three-stage hemispherical profile has been performed by single blow forming operation.

- Optimum pressure conditions were predicted to obtained uniform thickness distribution in a proposed parametric model.

- $\quad$ Finite element modelling results were found to be in fair agreement with the experimental results.

- $\quad$ Minimum forming time and uniform thickness profile obtained from function of friction coefficient.

- Analysis and obtained uniform thickness profile with a function of die entry radius.

\section{O INTRODUCTION}

Superplastic forming plays an important role in many industrial and aerospace applications. It is a superior technique for causing large amounts of deformation under low strain rates and flow stresses, in comparison with techniques such as deep drawing [1] and [2], hot rolling [3], cold rolling [4], incremental forming [2], [5] and [6] and other heat treatment processes [7].

Studies on superplastic forming techniques are frequently based on single-stage forming operations. For example, Jovane [8] has determined superplastic forming parameters, such as $\mathrm{k}$ and $\mathrm{m}$, by varying the applied pressure in increments and thus optimized the pressure at which change in strain rate becomes insignificant. Luckey et al. [9] have developed a two-stage complex dome employing a superplastic forming process in order to improve the thickness profile and prevent wrinkling effects in AA 5083 alloy sheets. Ragab [10] has examined sticking between the contact surface of the sheet and die in the single-stage forming of a cylindrical cup and further investigated thickness distribution under plane-strain conditions. Aoura et al. [11] have proposed a constant stress control method combined with a pressure prediction algorithm to maintain maximum strain rate during the bulge forming process to obtain uniform thickness distribution in a conical cup in a single stage.

Karthikeyan et al. [12] have reported microstructural changes for better mechanical properties and formability characteristics of AA 6063-T6 alloy in a multiple friction stir-processing method of a hemispherical cup. Yogesha and Bhattacharya [13] have analysed a single stage hemispherical dome for its superplastic deformation characteristics in terms of micro-structure, forming time, thickness strain, pole thickness, thinning factor and temperature using a TiAl-Mn alloy. Senthil Kumar et al. [14] have studied the forming of a single stage hemispherical die, both experimentally and using the finite element method in terms of relative height, forming time, pressure, temperature and thickness distribution.

Pradeep et al. [15] have investigated the effect of coefficient of friction between the surface of the die and the sheet, and reported uniform thickness distribution at lower friction values. Xiaomei and Steven [16] have investigated the effects of sheet thickness, flow stress distribution, target stresses, grain size and contact accuracy between the alloy sheet and the ceramic die on the superplastic forming of the Ti-6Al-4V alloy by incorporating a dental ridge augmentation membrane (RAM). Luckey et al. [17] have developed a pressure prediction algorithm in 
order to maintain a predetermined strain rate under the average scheme method and reported $20 \%$ of the average scheme to improve the pressure cycle and maintain target strain rate throughout the forming cycle.

$\mathrm{Ng}$ et al. [18] have studied the prediction of localized thinning and thickness distribution in a superplastic forming sheet by introducing a new set of element sizes, mass scaling, and adaptive meshing processes. Jarrar et al. [19] have reported an approach for predicting the gas pressure profile variation as a function of time. This approach combines the pressure with a material constitutive model implemented in ABAQUS for predicting the pressure profile. $\mathrm{Wu}$ [20] has analysed the cavitations of SP5083 aluminium alloy in a single stage rectangular pan. It has been found that a two-step strain rate process has reduced the cavitations during superplastic forming. Dezelak et al. [21] have analysed the effect of twist spring back method for a metal sheet by using elastic-plastic shell elements in a FEM simulation. Hojjati et al. [22] investigated the optimization of SPF parameters by employing the hydro forming process for an AA5083 alloy and proved that the maximum strain rate could be controlled via a logarithmic algorithm.

Though extensive research has been carried out using the single-stage superplastic forming of aluminium alloys, such as AA 5083, studies on these materials involving two or more stages of forming in a hemispherical die are very limited. Applications such as aircraft wings, automobile exterior components, and turbine blades have various dimensions to be created in a single-forming operation. In such situations, prior knowledge based on a multistage (three-stage) superplastic forming operations will be highly relevant. In this research work, therefore, an attempt has been made to investigate the three-stage superplastic forming of AA5083 (three different die radii with parametric design) in a hemispherical die. Parameters such as forming height, pole thickness, thickness distribution, average thickness, thinning factor, and forming time, have been studied as a function of forming pressure, friction coefficient and die entry radius in a three-stage parametric model.

\section{EXPERIMENTAL PROCEDURE}

Uniaxial tensile tests were carried out at different temperatures in order to identify the optimum temperature for the superplastic forming of AA5083, the chemical composition of which is given in Table1. From the hot tensile test results, the optimum temperature was identified as $450{ }^{\circ} \mathrm{C}$ at an initial strain rate of $(\dot{\varepsilon}) 1.2 \times 10^{-3} \mathrm{~s}^{-1}$, strain rate sensitivity index, $m$, of 0.3 , material constant, $k$, of $159 \mathrm{MPa} / \mathrm{s}$ and flow equation of $\sigma=k \dot{\varepsilon}^{m}$, where $\sigma$ is flow stress.

Table 1. Chemical composition of AA 5083 alloy (\% weight)

\begin{tabular}{|c|c|c|c|c|c|c|c|c|}
\hline $\mathrm{Si}$ & $\mathrm{Fe}$ & $\mathrm{Cu}$ & $\mathrm{Mg}$ & $\mathrm{Mn}$ & $\mathrm{Cr}$ & $\mathrm{Zn}$ & $\mathrm{Ti}$ & $\mathrm{Al}$ \\
\hline$\stackrel{\stackrel{2}{\simeq}}{0}$ & $\stackrel{\stackrel{\infty}{\circ}}{\circ}$ & চᄒ & $\underset{\Gamma}{\frac{\pi}{0}}$ & $\stackrel{\mathscr{S}}{\mathrm{N}}$ & 茖 & 눙 & ๙్రి & 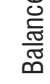 \\
\hline
\end{tabular}

The experimental setup is shown schematically in Fig. 1. The superplastic forming die consists of male and female parts. The female part consists of three die radii of $18 \mathrm{~mm}, 27 \mathrm{~mm}$ and $30 \mathrm{~mm}$ with the first die entry radius of $3 \mathrm{~mm}$, while the second and third die entry radius are each of $1 \mathrm{~mm}$. The die radius is in the ratio of 6:9:10 and represented in the parametric design as $6 \alpha: 90: 10 \alpha$, where $\alpha$ is the parametric value. Correspondingly, the three dome depths are in the ratio of 4:3:3 (12 $\mathrm{mm}, 9 \mathrm{~mm}$ and $9 \mathrm{~mm}$ in height).

A $70-\mathrm{mm}$ diameter slot was provided in the female die with a depth of $1 \mathrm{~mm}$. The entire die setup, consisting of both the male and female parts, was surrounded without any air gap by a band heater and the entire assembly was placed in a $100 \mathrm{kN}$ hydraulic press under air tight conditions. The die setup was heated up to the desired temperature of $450{ }^{\circ} \mathrm{C}$ and maintained until the experiment was completed. The $70-\mathrm{mm}$ diameter and $1.5 \mathrm{~mm}$ thick specimens kept between male and female parts. Next, constant argon gas pressure was applied and used to measure the different stages of bulge height as a function of forming time through the LVDT arrangement.

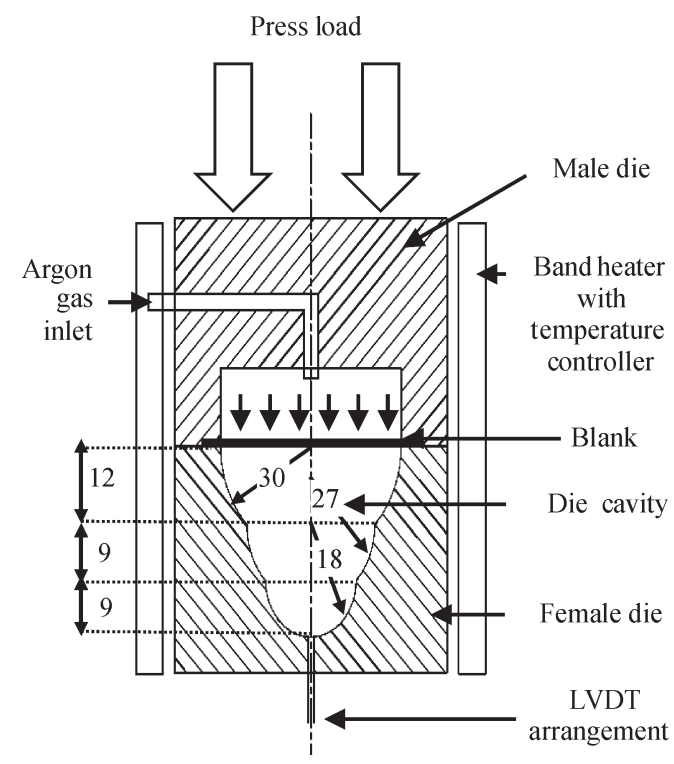

Fig. 1. Schematic arrangement of three stage die 
For three-stage superplastic forming, pressure was varied from $0.1 \mathrm{MPa}$ to $0.8 \mathrm{MPa}$ and for each pressure, superplastic forming experiments were conducted at $(5,8,9,10,12,15,18,20,25,27,29$ and 30) $\mathrm{mm}$ of bulge height to predict the optimum pressure required for uniform thickness distribution. For each bulge height, individual components were formed and the parameters of pole thickness, thickness distribution, relative bulge height, relative bulge radius, forming time, average thickness and thinning factor were determined.

\section{FINITE ELEMENT ANALYSES}

The three-stage superplastic forming process has been simulated by finite element analysis (FEA) using ABAQUS. In the pre-processing stage of FEA, the geometry of the die is assumed as discrete rigid and the blank material as an elasto-plastic deformation body. 3D finite element analysis for a quarter section has been performed. The blank was meshed with the shell element [17] with 1597 nodes; the rigid die was meshed with the R3D3 element and the nodes formed in the die were 1542 .

The blank was placed over the die, its periphery was firmly clamped along the rigid die with the boundary conditions $\left(\mathrm{U}_{1}=\mathrm{U}_{2}=\mathrm{U}_{3}=\mathrm{UR}_{1}=\mathrm{UR}_{2}=\mathrm{UR}_{3}\right.$ $=0$ ) as shown in Fig. 2, and constant pressure was then applied uniformly over the entire blank surface. The blank behaved like an elasto-plastic material in the manner expected according to the Newton-Raphson method.

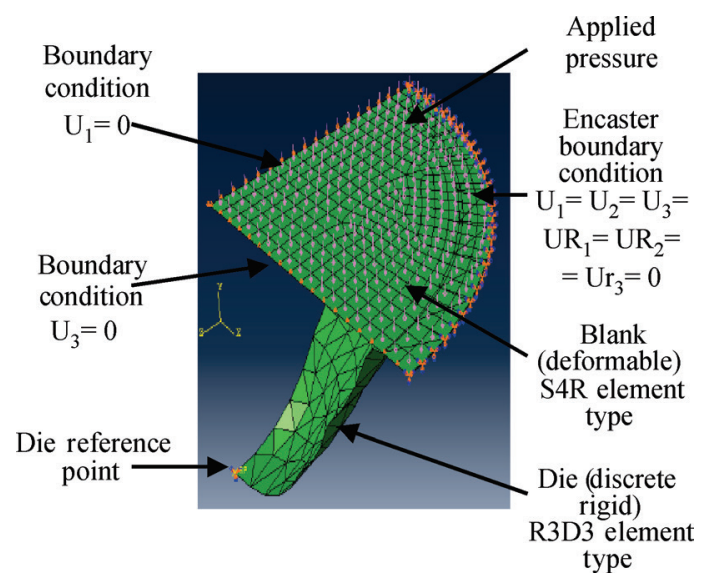

Fig. 2. Boundary conditions for superplastic forming process

FEA was carried out using Coulomb's friction condition. The coefficient of friction values were kept at $0,0.2$ and 0.4 between the die surface and the blank. An optimum value of the coefficient of friction was determinedin order to obtain uniform thickness in all the three stages of the profile.

In the solution phase, displacement with respect to time, pole thickness, thickness distribution, forming time, relative bulge height and relative bulge radius were declared as variables to be determined at constant pressure, different coefficients of friction for each pressure and different die entry radius. In

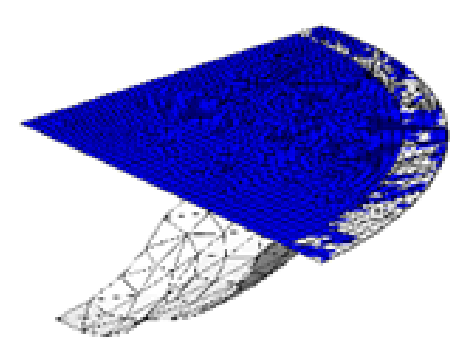

a1) Before forming ( $t=0)$

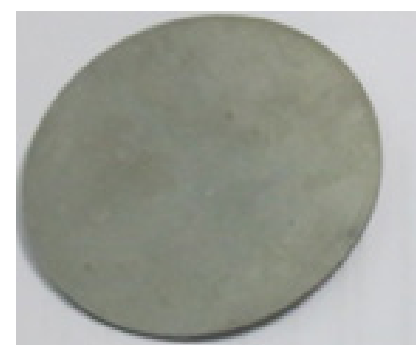

b1) Before forming ( $t=0$ )

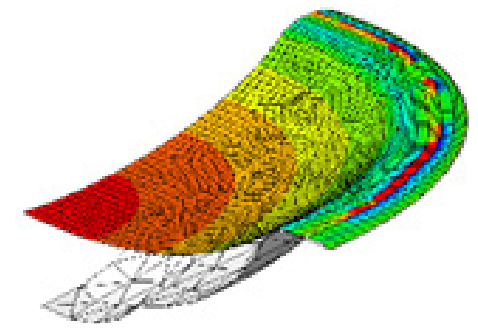

a2) During forming ( $t=12 \mathrm{~min}$ )

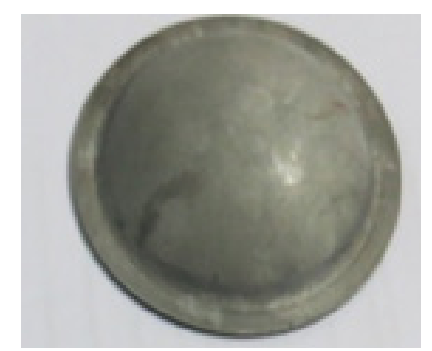

b2) During forming ( $t=12 \mathrm{~min}$ )

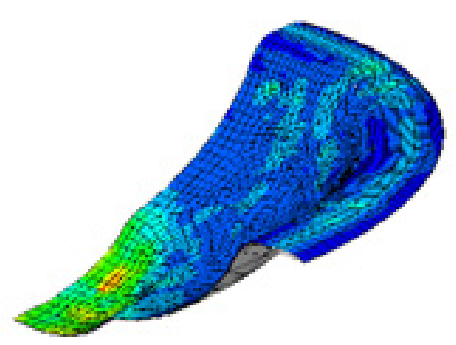

a3) End of forming ( $t=19.9 \mathrm{~min}$ )

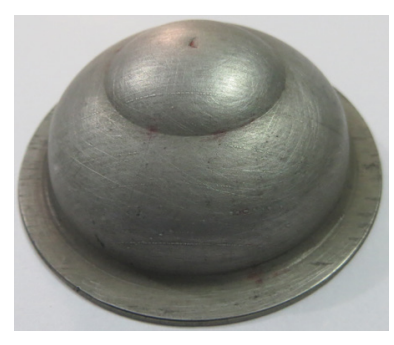

b3) End of forming ( $t=20.2 \mathrm{~min})$

Fig. 3. Various stages of superplastic forming in a) FEA and b) during experiment at $0.5 \mathrm{MPa}$ with function of time 
the post-processor phase, various SPF parameters are obtained.

Fig. $3 \mathrm{a}$ and $\mathrm{b}$ shows different stages of superplastic forming components both in FEA and actual experiments.

\section{RESULTS AND DISCUSSIONS}

The three-stage superplastic forming behaviour of the AA5083 alloy has been experimentally studied as a function of pressure, forming height, coefficient of friction and die entry radius. During the experiments, the optimum temperature of $450{ }^{\circ} \mathrm{C}$ for a specific forming period was maintained until the perfect forming of the profile was achieved. This is in contrast with single-stage superplastic forming, for which the formation of the profile is relatively simple. The results of the experiments conducted under closely monitored conditions are discussed in the following section.

\subsection{Relationship between Forming Pressure and Forming Time to Reach Maximum Height}

Relative forming height, the ratio between instantaneous forming height and the actual height $\left(h_{i} / h\right)$, has been followed as a function of forming time at different pressure levels; the results are shown in Table 2 and in Fig. 4. From Table 2, it can be observed that the forming time decreases with increasing forming pressure in the stepped profile.

For example, the time required to reach the final height is about 124 minutes at a pressure of $0.1 \mathrm{MPa}$ but on increasing to $0.2 \mathrm{MPa}$, the time dropped by half, to 65 minutes. Therefore, when the pressure is increased, the time decreases significantly and a better shape of the profile is obtained.

The final forming height values determined from actual experiments have been found to be very close to the values obtained using finite element model, with a maximum percentage error of $2.73 \%$ at $0.1 \mathrm{MPa}$.

The prediction of the forming height as a function of pressure and forming time by the FEM and the values obtained through the experiments agree very well with the minimum error at still higher pressures, as can be seen from Table 2 .

Variation in relative bulge height as a function of time and pressure is plotted in Fig. 4. It is observed that the forming time decreases with increasing pressure. The sigmoidal variation of bulge height with time may be attributed to the relatively large stresses existing in the early stages of forming, as the relative height $\left(h_{i} / h\right)$ is small.
Table 2. Effect of pressure on final forming time to reach the maximum height $\left(h_{i} / h=1\right)$

\begin{tabular}{cccc}
\hline \multirow{2}{*}{$\begin{array}{c}\text { Pressure } \\
{[\mathrm{MPa}]}\end{array}$} & \multicolumn{2}{c}{ Final forming time [min] } & $\begin{array}{c}\text { Error in forming } \\
\text { time [\%] }\end{array}$ \\
\cline { 2 - 3 } & Experimental & $\mathrm{FEM}$ & 2.73 \\
\hline 0.1 & 124.4 & 121.1 & 2.35 \\
\hline 0.2 & 65.3 & 63.8 & 2.65 \\
\hline 0.3 & 38.8 & 37.8 & 2.44 \\
\hline 0.4 & 25.2 & 24.6 & 1.51 \\
\hline 0.5 & 20.2 & 19.9 & 1.89 \\
\hline 0.6 & 16.1 & 15.8 & \\
\hline
\end{tabular}

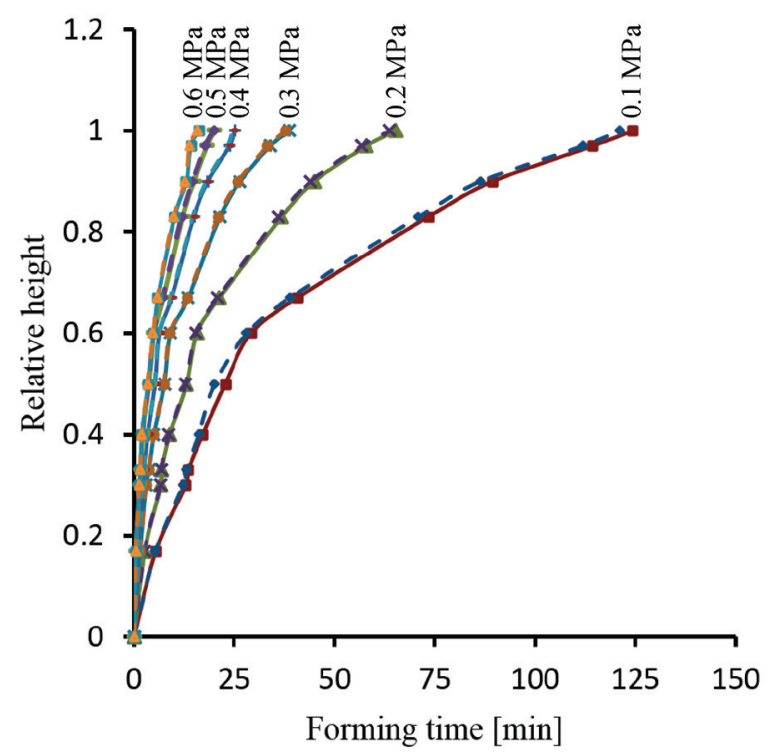

Fig. 4. Variation of relative bulge height $\left(h_{i} / h\right)$ with time

\subsection{Relationship between Forming Height and Relative Radius $\left(r_{i} / r\right)$}

The relative radius is defined as the ratio of instantaneous radius $r_{i}$ to the corresponding base radius $r$ of each stage. For the determination of the instantaneous radius, the dome is divided into thin concentric rings during blow forming, and the radius of any particular ring $r_{i}$ has been measured with reference to the central axis. The change in relative radius as a function of forming height is shown in Fig. 5. It is evident that both height and radius change simultaneously during blow forming throughout the first stage of the radius. At the end of first stage (Point B), there is a small rise in radius with respect to height, which continues to rise gradually until the end of second stage (Point $\mathrm{C}$ ) beyond which a predominant change in radius can be observed as the height increases further. After this significant rise at the beginning of stage 3 , the radius starts 
decreasing rapidly as the increase in height becomes more prominent than the change in radius until reaching the final height. The relative radius obtained experimentally and the finite element model follow the same trend as a function of forming height with minor variations observed from stage 1 to stage 2 and stage 2 to stage 3 of forming.

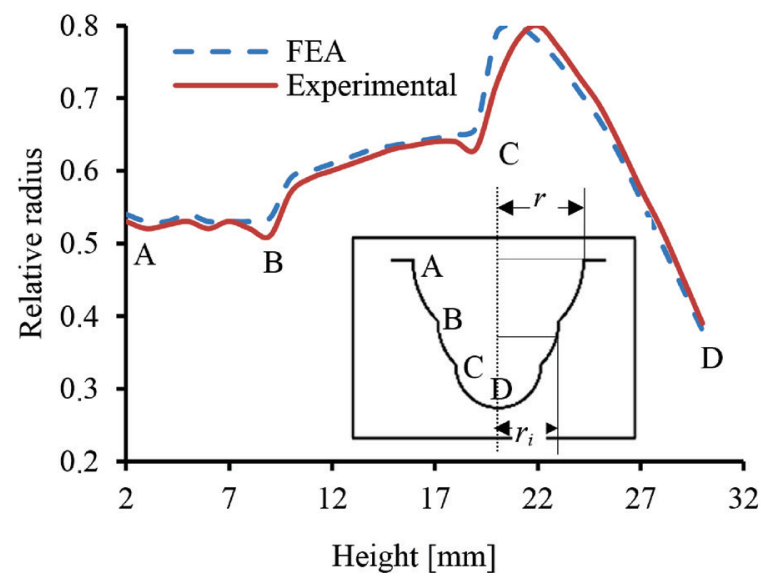

Fig. 5. Relative radius as a function of forming height at $450^{\circ} \mathrm{C}$

\subsection{Relationship between Forming Height and Pole Thickness}

It is generally observed that the pole thickness gradually decreases as a function of forming height in most of the single-stage forming operations. In the present work, however, discontinuities are observed in an otherwise gradual reduction of thickness at pole points where the forming process changes from stage 1 to stage 2 and stage 2 to stage 3, as shown in Fig. 6 .

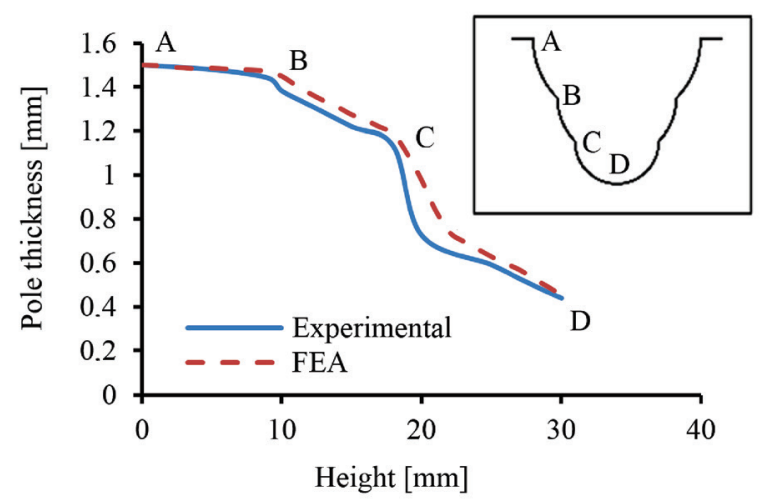

Fig. 6. Pole thickness as a function of forming height at $450^{\circ} \mathrm{C}$

The pole thickness does not show any appreciable reduction as a function of forming height during the first stage. However, the reduction in pole thickness is significant when the forming process approaches the second stage, and it is predominant during the third stage of forming. It is clearly indicated that thickness decreases gradually until the sample contacts the first stage radius of die where the blank is more likely to stick to the die surface leading to a drop in thickness; this is also observed during the second stage. The blank continues blow forming during the third stage, and the thickness decreases continuously as a function of the forming height, which ultimately reaches the pole height. It is seen from Fig. 6 that the experimental values are in good agreement with the FEA results, with the maximum percentage error of 1.9.

\subsection{Effect of Time and Pressure on Pole Thickness}

The variation of pole thickness as a function of time at different pressures ranging from $0.1 \mathrm{MPa}$ to 0.6 $\mathrm{MPa}$ is presented in Fig. 7. The forming time has been found to decrease upon increasing the pressure. Both the experimentally determined and the finite element modelled dome thickness, average thickness and thinning factor values of the fully formed final components at different pressures are given in Tables 3 and 4, respectively. On comparison of these values, it can be seen that the experimental and FEA values are in good agreement.

The data in Tables 3 and 4 indicate that though variation in thinning factor is not significant as a function of applied pressure, the highest value is found to be at a pressure of $0.5 \mathrm{MPa}$ followed by a drop in thinning factor when the pressure is increased further. The thinning factor, the ratio of thickness at the dome to the average sheet thickness, plays a vital role in predicting the uniformity of thickness in the formed profile with the highest value indicating more uniform thickness in the product.

Therefore, from the experimental result, it may be understood that, in this case, the uniform thickness has been achieved when optimum applied pressure is at $0.5 \mathrm{MPa}$. As the pressure is increased beyond 0.6 $\mathrm{MPa}$, tearing in the blank sheet occurs at a particular height and pole thickness, as shown in Fig. 8, and the corresponding experimental values of forming height, forming time and thickness are shown in Table 5. Finally it is observed that $0.5 \mathrm{MPa}$ constant pressures was the optimum value at the given specified model.

\subsection{Effect of Friction Coefficient on Thickness Profile}

Friction is an important parameter to be considered during the superplastic forming of components. The SPF process is numerically simulated using three 
different coefficient of friction $(\mu)$ values. The five important forming parameters, such as thickness distribution, dome thickness, average thickness, thinning factor and forming time are observed by varying the coefficient of friction. The friction is assumed to be uniform along the contact surface with coefficient values of 0.0, 0.2 and 0.4 for FEA analysis. Fig. 9 shows the thickness distribution obtained by FEA with various coefficients of friction values $(0$, $0.2,0.4)$ under $0.5 \mathrm{MPa}$. Once the material starts flowing, the initial contact between the die and the blank takes place at the die entry point. Due to sliding under pressure, the thickness of the profile varies as a function of friction coefficient.
The thickness decreases if the coefficient of friction is high and vice versa. The results of the FEA analysis show that the thickness is reduced as the coefficient of friction is increased, and, therefore, a lesser coefficient of friction results in uniform thickness.

Table 6 shows the effect of the coefficient of friction on the dome thickness, the average thickness, and the thinning factor obtained using the FEA model. From the results, it is observed that the dome thickness and thinning factor decrease significantly with increases in the friction coefficient while the average thickness shows only a negligible drop. Increasing the coefficient of friction creates localised thinning in the dome of the sheet and, therefore, results in large

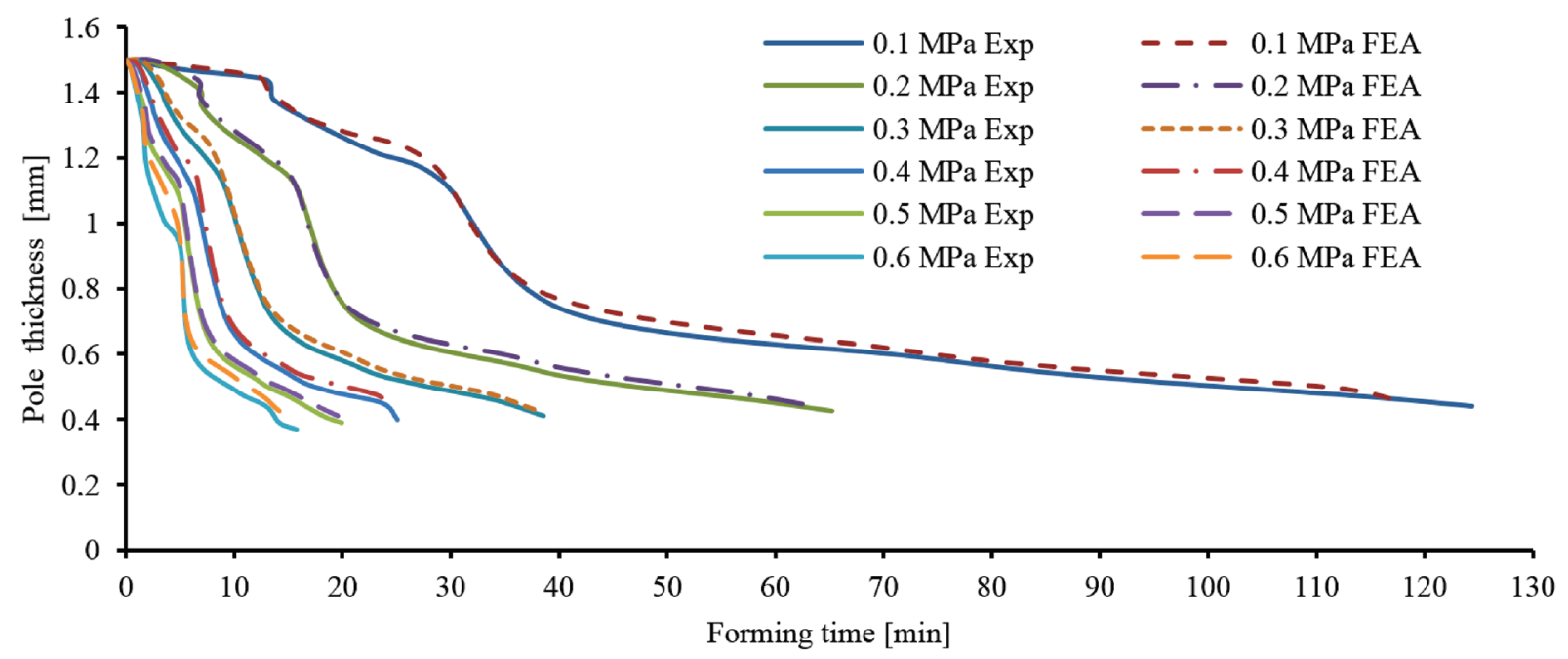

Fig. 7. Pole thickness as a function of forming time at $450^{\circ} \mathrm{C}$

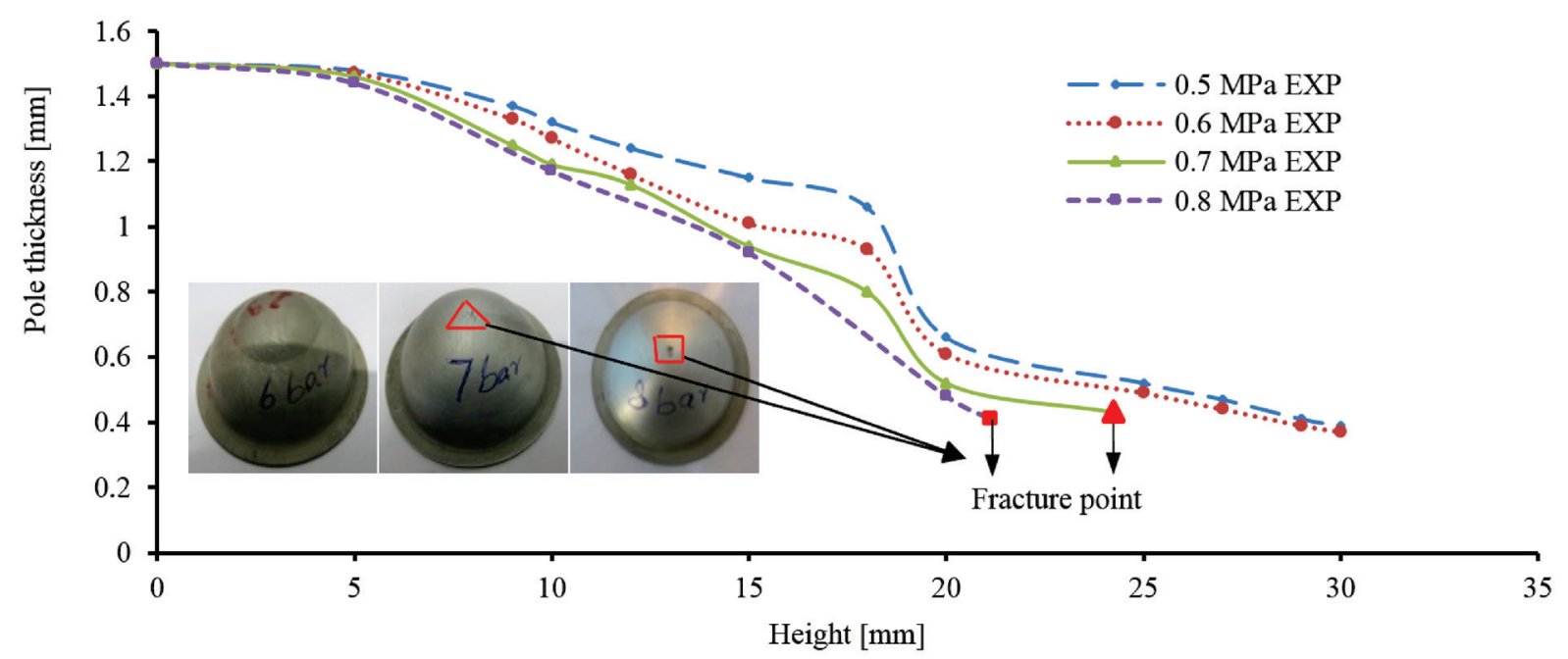

Fig. 8. Pole thickness as a function of forming height at tearing point and $450^{\circ} \mathrm{C}$ 
variations in the dome thickness. Thickness variations can be minimized achieved by ensuring lower friction coefficient. In addition, a higher coefficient of friction will also affect the forming time in a negative manner as shown in Table 7.

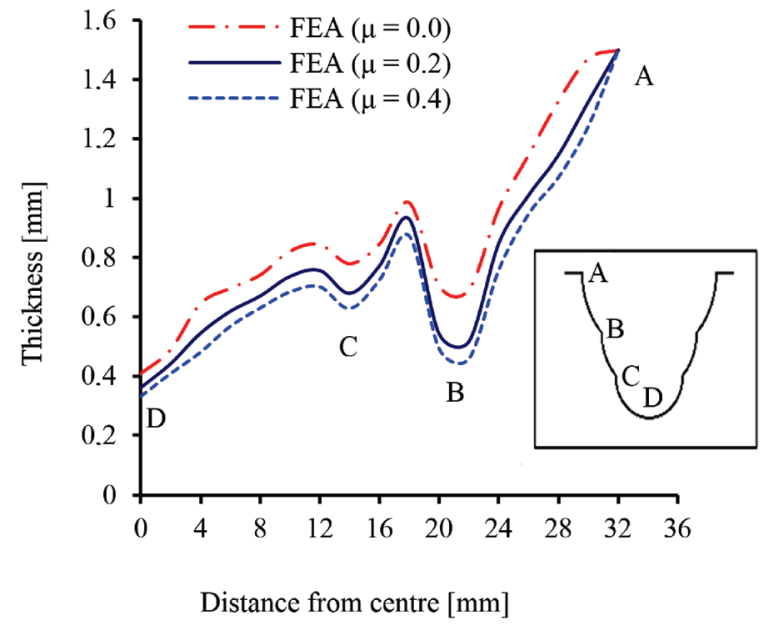

Fig. 9. Thickness distribution from the centre as a function of friction coefficient

Table 3. Effect of pressure on forming characteristics at $450{ }^{\circ} \mathrm{C}$ from Experimental data

\begin{tabular}{lcccccc}
\hline Description & $\begin{array}{c}0.1 \\
{[\mathrm{MPa}]}\end{array}$ & $\begin{array}{c}0.2 \\
{[\mathrm{MPa}]}\end{array}$ & $\begin{array}{c}0.3 \\
{[\mathrm{MPa}]}\end{array}$ & $\begin{array}{c}0.4 \\
{[\mathrm{MPa}]}\end{array}$ & $\begin{array}{c}0.5 \\
{[\mathrm{MPa}]}\end{array}$ & $\begin{array}{c}0.6 \\
{[\mathrm{MPa}]}\end{array}$ \\
\hline $\begin{array}{l}\text { Dome thickness } \\
\text { [mm] }\end{array}$ & 0.44 & 0.43 & 0.41 & 0.40 & 0.39 & 0.37 \\
\hline $\begin{array}{l}\text { Average thickness } \\
\text { [mm] }\end{array}$ & 0.99 & 0.98 & 0.92 & 0.90 & 0.87 & 0.83 \\
\hline Thinning factor [\%] & 44.63 & 44.67 & 44.69 & 44.71 & 44.73 & 44.71 \\
\hline
\end{tabular}

Table 4. Effect of pressure on forming characteristics at $450{ }^{\circ} \mathrm{C}$ in FEA

\begin{tabular}{lcccccc}
\hline Description & $\begin{array}{c}0.1 \\
{[\mathrm{MPa}]}\end{array}$ & $\begin{array}{c}0.2 \\
{[\mathrm{MPa}]}\end{array}$ & $\begin{array}{c}0.3 \\
{[\mathrm{MPa}]}\end{array}$ & $\begin{array}{c}0.4 \\
{[\mathrm{MPa}]}\end{array}$ & $\begin{array}{c}0.5 \\
{[\mathrm{MPa}]}\end{array}$ & $\begin{array}{c}0.6 \\
{[\mathrm{MPa}]}\end{array}$ \\
\hline $\begin{array}{l}\text { Dome thickness } \\
\text { [mm] }\end{array}$ & 0.45 & 0.44 & 0.43 & 0.42 & 0.41 & 0.39 \\
\hline $\begin{array}{l}\text { Average thickness } \\
\text { [mm] }\end{array}$ & 0.99 & 0.97 & 0.94 & 0.92 & 0.89 & 0.85 \\
\hline Thinning factor [\%] & 45.62 & 45.65 & 45.68 & 45.70 & 45.72 & 45.71 \\
\hline
\end{tabular}

Table 5. Bulge height, forming time and thickness at fracture point

\begin{tabular}{lcccc}
\hline Description & $\begin{array}{c}\text { Pressure } \\
{[\mathrm{MPa}]}\end{array}$ & $\begin{array}{c}\text { Forming } \\
\text { height } \\
{[\mathrm{mm}]}\end{array}$ & $\begin{array}{c}\text { Forming } \\
\text { time } \\
{[\mathrm{min}]}\end{array}$ & $\begin{array}{c}\text { Pole } \\
\text { thickness } \\
{[\mathrm{mm}]}\end{array}$ \\
\hline Fracture & 0.7 & 24.3 & 7.3 & 0.43 \\
\cline { 2 - 5 } point & 0.8 & 21.2 & 6.3 & 0.44 \\
\hline
\end{tabular}

Table 6. Effect of friction coefficient on forming characteristics at $450{ }^{\circ} \mathrm{C}$

\begin{tabular}{lccc}
\hline \multirow{2}{*}{ Description } & \multicolumn{3}{c}{ FEA } \\
\cline { 2 - 4 } & $\mu=0.0$ & $\mu=0.2$ & $\mu=0.4$ \\
\hline Dome thickness [mm] & 0.41 & 0.36 & 0.33 \\
\hline Average thickness [mm] & 0.92 & 0.91 & 0.9 \\
\hline Thinning factor [\%] & 44.53 & 39.61 & 36.64 \\
\hline
\end{tabular}

Table 7. Forming time at different friction coefficient

\begin{tabular}{cc}
\hline Coefficient of friction (FEA) & Forming time [min] \\
\hline$\mu=0.0$ & 20 \\
\hline$\mu=0.2$ & 22 \\
\hline$\mu=0.4$ & 23 \\
\hline
\end{tabular}

\subsection{Effect of Die Entry Radius and Time on Pole Thickness}

In the superplastic forming process, the die entry radius is bound to affect the SPF parameters, such as the thickness of the formed profile, the pole thickness and forming time. In order to maximise the uniformity of thickness in a three-stage dome profile, it is important to understand the effect of the die entry radius of a female die on the characteristics of the formed profile.

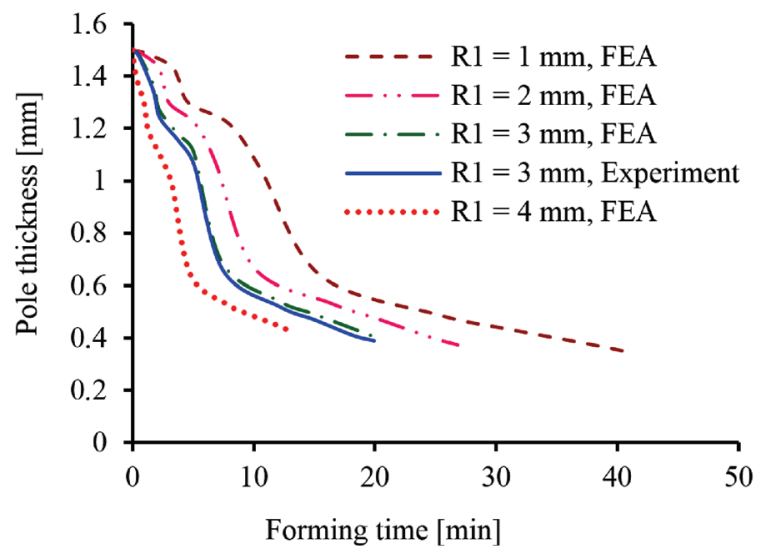

Fig. 10. Pole thickness with a function of forming time at different die entry radii

In the experimental and FEA studies, the assigned values for die entry radius are $3 \mathrm{~mm}, 2 \mathrm{~mm}$ and 1 $\mathrm{mm}$ for the first, second and third die entry points, respectively. In the FEA model, the first die entry values have been changed to $1 \mathrm{~mm}, 2 \mathrm{~mm}$ and $4 \mathrm{~mm}$, while the second and third die entry radius values have been kept at $1 \mathrm{~mm}$ for all these die entry radius values, the pole thickness is given as a function of forming time is in Fig. 10. It is evident from Fig.10 that the total forming time decreases with increases in 
the die entry radius, and that the pole thickness has been found to increase with the increase in die entry radius. The thickness of the profiles, as obtained from the FEA studies, from the centre point of dome along the profile towards the edge of it is shown in Fig. 11.

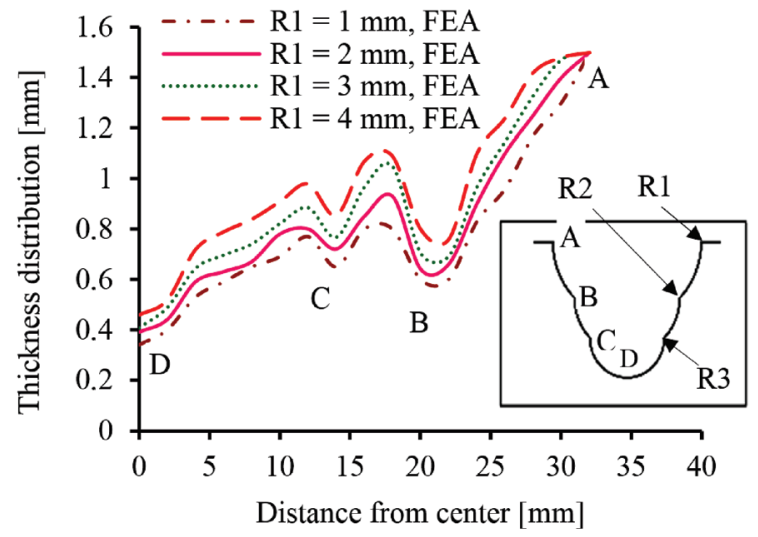

Fig. 11. Thickness distribution with respect to distance from centre at different die entry radii

Table 8. Effect of die entry radius on forming characteristics at $450^{\circ} \mathrm{C}$

\begin{tabular}{lcccc}
\hline \multirow{2}{*}{ Description } & \multicolumn{5}{c}{ FEA (R2=R3 $=1 \mathrm{~mm})$} \\
\cline { 2 - 5 } & $\begin{array}{c}\mathrm{R} 1=1 \\
\mathrm{~mm}\end{array}$ & $\begin{array}{c}\mathrm{R} 1=2 \\
\mathrm{~mm}\end{array}$ & $\begin{array}{c}\mathrm{R} 1=3 \\
\mathrm{~mm}\end{array}$ & $\begin{array}{c}\mathrm{R} 1=4 \\
\mathrm{~mm}\end{array}$ \\
\hline Dome thickness [mm] & 0.34 & 0.37 & 0.41 & 0.45 \\
\hline Average thickness [mm] & 0.78 & 0.84 & 0.92 & 0.97 \\
\hline Thinning factor [\%] & 42.3 & 43.9 & 44.5 & 46.9 \\
\hline
\end{tabular}

Fig. 11 shows the simulated results obtained from FEA studies on the effect of die entry radius on the thickness distribution in the profile with reference to its centre. It is evident that the thickness is at its maximum at the edges of the profile and that it decreases as the reference points move close to the centre. However, the reduction in thickness of the profile as one move from the edge of the profile towards its centre is not gradual and continuous. At the second and third die entry regions of the female die, the thickness is first found to undergo a significant drop followed by a corresponding increase before it starts decreasing again gradually. These two discontinuity-like behaviours could be attributed to the localized thinning around the die entry regions. Table 8 shows the FEA results on the variation of dome thickness, average thickness and thinning factor as a function of die entry radius. From the results, it is observed that dome thickness and thinning factor increase with an increase in the die entry radius. The higher thinning factor, due to higher die entry radius, indicates more uniformity in thickness and, therefore, it canbe concluded that the die entry radius has a vital effect in controlling the thickness of the formed profile.

\section{CONCLUSIONS}

Experimental investigations and finite element analysis of the three-stage forming process have been carried out and analysed in terms of important forming characteristics. Three-stage superplastic forming of the 5083 aluminium alloy into a hemispherical die has been carried out at different forming pressures in order to predict the optimum forming pressure required to obtain uniform profile thickness. FEA has been used as a guide for performing the three-stage superplastic forming process and studied the thickness uniformity in the profile.

Discontinuities in the thickness of the formed profile have been observed due to the transition of radius from one stage to the next. Experimental studies have revealed that an optimum pressure of 0.5 $\mathrm{MPa}$ for achieving uniform thickness in the profile exists. Moving away from the optimum pressure leads either to variations in thickness or instabilities in the profile.

For the three-stage simulation under identical forming conditions, it has been shown that the uniformity in thickness of the profile is possible by taking the coefficient friction value below 0.1 and keeping the die entry radius greater than $4 \mathrm{~mm}$. In the three-stage superplastic forming, the parameters obtained are in good correlation for both the experimental and FE simulation method.

\section{REFERENCES}

[1] Cebeli, Ö., Engin, Ü. (2011). Optimization and modeling of angular deep drawing process for square cups. Journal of Materials and Manufacturing Process, vol. 26, no. 9, p. 11171125, DOl:10.1080/10426914.2010.532526.

[2] Petek, A., Gantar, G., Pepelnjak, T., Kuzman, K. (2007). Economical and ecological aspects of single point incremental forming versus deep drawing technology. Trans Tech Publications, vol. 344, p. 931-938, D0l:10.4028/www. scientific.net/KEM.344.93.

[3] Wang, L.R., Zhao, Y.Q., Zhou, L. (2012). Effect of hot rolling on the structure of TC21 alloy with acicular alpha. Journal of Materials and Manufacturing Process, vol. 27, no. 2, p. 154159, D0I:10.1080/10426914.2011.566662.

[4] Nițu, E., lordache, M., Marincei, L., Charpentier, I., Le Coz, G., Ferron, G., Ungureanu, I. (2011). FE-modeling of cold rolling by in-feed method of circular grooves. Strojniški vestnik Journal of Mechanical Engineering, vol. 57, no. 9, p. 667-673, DOI:10.5545/sv-jme.2010.244. 
[5] Petek, A., Pepelnjak, T., Kuzman, K. (2005). New method for determination of fld in digital environment. Strojniški vestnik Journal of Mechanical Engineering, vol. 51, no. 6, p. 330-345.

[6] Emmens, W.C., Sebastiani, G., Van den Boogaard, A.H. (2010). The technology of incremental sheet forming. Journal of Materials Processing Technology, vol. 210, no. 8, p. 981-997, D0I:10.1016/j.jmatprotec.2010.02.014.

[7] Burtchen, M., Hunkel, M., Lübben, T., Hoffmann, F., Zoch, H.W. (2009). Simulation of quenching treatments on bearing components. Strojniški vestnik - Journal of Mechanical Engineering, vol. 55, no. 3, p. 155-159.

[8] Jovane, F. (1968). An approximate analysis of the superplastic forming of a thin circular diaphragm. Theory and experiments. International Journals of Mechanical Science, vol. 10, no. 5, p. 403-427, DOI:10.1016/0020-7403(68)90005-2.

[9] Luckey, S.G.Jr., Friedman, P.A., Weinmann, K.J. (2009). Design and experimental validation of a two-stage superplastic forming die. Journals of Materials Processing Technology, vol. 209, no. 4, p. 2152-2160, D0l:10.1016/j. jmatprotec.2008.05.019.

[10] Ragab, A.R. (2002). Thermoforming of superplastic sheet in shaped dies. Metal Materials Technology, vol. 10, no. 1, p. 340-348, DOI:10.1179/030716983803291262.

[11] Aoura, Y., Ollivier, D., Ambari, A., Dal Santo, P. (2004). Determination of material parameters for 7475 Al alloy from bulge forming tests at constant stress. Journal of Materials Processing Technology, vol. 145, no. 3, p. 352-359, D0I:10.1016/J.jmatprotec.2003.09.002.

[12] Karthikeyan, L., Senthil Kumar, V.S., Padmanabhan, K.A. (2013). Investigations on superplastic forming of friction stirprocessed AA6063-T6 aluminium alloy. Journal of Materials and Manufacturing Process, vol. 28, no. 3, p. 294-298, DOI:10.1080/10426914.2012.667895.

[13] Yogesha, B., Bhattacharya, S.S. (2011). Superplastic hemispherical bulge forming of a Ti-Al-Mn alloy. International Journal of Scientific \& Engineering Research, vol. 2, no. 12, p. 1-4.

[14] SenthilKumar, V.S., Viswanathan, D., Natarajan, S. (2006). Theoretical prediction and FEM analysis of superplastic forming of AA7475 aluminum alloy in a hemispherical die.
Journal of Material Processing Technology, vol. 173, no. 3, p. 247-251, D0I:10.1016/j.jmatprotec.2005.04.112.

[15] Pradeep, L., Menezes, K., Satish, V.K. (2010). Influence of die surface textures during metal forming-a study using experiments and simulation. Journal of Materials and Manufacturing Process, vol. 25, no. 9, p. 1030-1039, DOl:10.1080/10426914.2010.499037.

[16] Xiaomei, L., Steven, S. (2010). Numerical simulation of the superplastic forming of a dental ridge augmentation membrane. Journal of Materials and Manufacturing Process, vol. 25, no. 12, p. 1470-1476, Dol:10.1080/10426914.2010. 512653.

[17] Luckey, S.G.Jr., Friedman, P.A., Weinmann, K.J. (2007). Correlation of finite element analysis to superplastic forming experiments. Journals of Materials Processing Technology, vol. 194, no. 1-3, p. 30-37, Dol:10.1016/j.jmatprotec.2007.03.122.

[18] Ng, J.C., Luckey,S.G., Kridli, G.T., Friedman, P.A. (2011). Validation of a modified material model for use with shell elements to improve the predictive accuracy of the thickness distribution in superplastic forming of sheet metals. Journal of Materials Processing Technology, vol. 211, no. 8, p. 13861394, DOI:10.1016/J.jmatprotec.2011.03.012.

[19] Jarrar, F.S., Louis, G.H.Jr., Marwan, K.K., Allan, F.B. (2010). New approach to gas pressure profile prediction for high temperature AA5083 sheet forming. Journal of Material Processing Technology, vol. 210, no. 6-7, p. 825-834, D0I:10.1016/j.jmatprotec.2010.01.002.

[20] Wu, H.-Y. (2000). Influence of deformation variables on cavitation of a superplastic 5083 Aluminium alloy. Journal of Materials and Manufacturing Process, vol. 15, no. 2, p. 231245, DOI:10.1080/10426910008912985.

[21] Dezelak, M., Stepisnik, A., Pahole, I., Ficko, M. (2014). Evaluation of twist springback prediction after an AHSS forming process. International Journal of Simulation Modelling, vol. 13, no. 2, p. 171-182, Dol:10.2507/IJSIMM13(2)4.261.

[22] Hojjati, M.H., Zoorabadi, M., Hosseinipour, S.J. (2008). Optimization of superplastic hydro forming process of Aluminium alloy 5083. Journal of Materials Processing Technology, vol. 205, no. 1-3, p. 482-488, Dol:10.1016/ j.jmatprotec.2007.11.208. 